\title{
Perspective
}

PERSPECTIVE Actualité en histoire de l'art

$1 \mid 2021$

Portugal et espaces lusophones

\section{La notion de transfert culturel à l'épreuve du rococo minhote au Brésil, ou vice-versa}

The Concept of Cultural Transfer in the Light of the Minho Rococo in Brazil (or vice versa)

Der Gedanke eines Kulturtransfers des Rokoko von Minho nach Brasilien (oder umgekehrt) auf dem Prüfstand

Da noção de transferência cultural à experiência do rococó minhoto no Brasil, ou vice-versa

La nozione di transfer culturale alla prova col rococò minhote in Brasile, o viceversa

Raúl C. Sampaio Lopes

\section{(2) OpenEdition}

Journals

Édition électronique

URL : https://journals.openedition.org/perspective/23485

DOI : 10.4000/perspective.23485

ISSN : 2269-7721

Éditeur

Institut national d'histoire de l'art

Édition imprimée

Date de publication : 14 octobre 2021

Pagination : 169-178

ISBN : 978-2-917902-91-2

ISSN : $1777-7852$

Référence électronique

Raúl C. Sampaio Lopes, « La notion de transfert culturel à l'épreuve du rococo minhote au Brésil, ou vice-versa », Perspective [En ligne], 1 | 2021, mis en ligne le 31 décembre 2021, consulté le 14 mai 2022. URL : http://journals.openedition.org/perspective/23485; DOI : https://doi.org/10.4000/ perspective. 23485 


\title{
La notion de transfert culturel à l'épreuve du rococo minhote au Brésil, ou vice-versa
}

\author{
Raúl C. Sampaio Lopes
}

Le Nord-Ouest du Portugal, l'ancienne province du Minho, autour de la ville archiépiscopale de Braga, s'affirme, au cours de la seconde moitié du XVIII ${ }^{e}$ siècle, non seulement par la qualité et une certaine homogénéité de son art, mais aussi par la singularité de celui-ci, notamment dans le domaine de prédilection de l'art portugais d'ancien régime, le retable. Lieu d'un véritable transfert culturel en soi $^{1}$, dont l'analyse jadis menée par Marie-Thérèse Mandroux-França mériterait d'être revisitée ${ }^{2}$, cette production démontre en effet une assimilation créative des estampes et des traités parisiens et augsbourgeois « rococo » dont la radicalité n'est que rarement égalée ailleurs dans le pays, et qui lui vaut l'appellation quelque peu métonymique de "rococo minhote " ${ }^{3}$. J'ai moi-même mis en avant la particularité de ce monde artistique en soulignant la prédominance de l'art de la talha (la sculpture sur bois, notamment dans ses aspects aujourd'hui dits décoratifs) et la contamination des autres arts par ses valeurs ornementales mais aussi la structuration très particulière des échanges entre ses agents, valorisant à la fois des concepteurs qui sont comme des compositeurs, des chefs d'équipe qui jouent un rôle de chef d'orchestre, et des sculpteurs parfois comparables à des solistes virtuoses dans un ensemble $e^{4}$. Bien avant ces travaux, à la fin des années 1960 et au début des années 1970, Robert C. Smith avait mis en valeur les figures d'André Soares (1720-1769), génial " curieux » d'architecture, et de frère José Vilaça (1731-1809), " entailleur ${ }^{5}$ " professionnel entré dans l'ordre bénédictin alors qu'il travaillait aux retables de l'église-mère de l'ordre, sous la direction du même Soares, responsable du dessin de l'ensemble ${ }^{6}$. Eduardo Pires de Oliveira avait entretemps corrigé et complété les informations à propos d'André Soares dans une thèse de doctorat richement documentée qui couronnait de nombreuses années d'étude et de publications ${ }^{7}$.

Les habitants du Minho ont constitué l'un des plus gros contingents de continentaux à avoir alors migré vers le Brésil et à avoir fait profiter leur région d'une fortune nouvellement acquise, dans le meilleur des cas. Mais les quelques historiens intéressés par ces mouvements de migration, dont Smith et Pires de Oliveira, se sont concentrés essentiellement sur les échanges avec la région brésilienne du Minas Gerais ${ }^{8}$. 
Je voudrais tester ici la notion de transfert culturel, telle que définie par Michel Espagne9, sur deux retables " brésiliens " peu documentés auxquels certains auteurs supposent une origine dans l'art du Minho : le retable principal de la basilique São Bento d'Olinda (Pernambouc) (fig. 1) et le retable de la chapelle des reliques de l'église du monastère bénédictin de Rio de Janeiro (fig. 2). L'application d'une telle grille de lecture à ces deux retables serait-elle à même de révéler quelque chose sur les méthodes de l'histoire de l'art ? Postulant que la qualité de l'analyse d'un transfert culturel serait dépendante de la connaissance des intentions de ses acteurs et qu'on les connaîtrait essentiellement par des documents écrits, Béatrice Joyeux-Prunel soulevait cette crainte déjà en 2003 :

En revanche, sans la présence de l'écrit, peut-on encore pister un transfert culturel ? La méthode des transferts insiste sur leur matérialité. Mais son application sera-t-elle si facile quand le matériel devient justement premier ? Est-il possible d'analyser des transferts culturels en se fondant sur des sources non écrites?

La théorie des transferts risquerait-elle donc, en histoire de l'art, " de ne pas permettre de sortir de la question des influences et de l'extension des styles ", étant donné qu'on ne pourrait " postuler trop vite des relations que fondent seulement des similitudes visuelles, en oubliant la part du hasard et du goût individue ${ }^{10}$ "?

Je commencerai par préciser le problème des cultures envisagées. L'idée de transfert culturel implique qu'il y ait transfert de quelque chose

1. Retable principal de l'église São Bento, Olinda (Brésil, Pernambouc), 1783-1786.

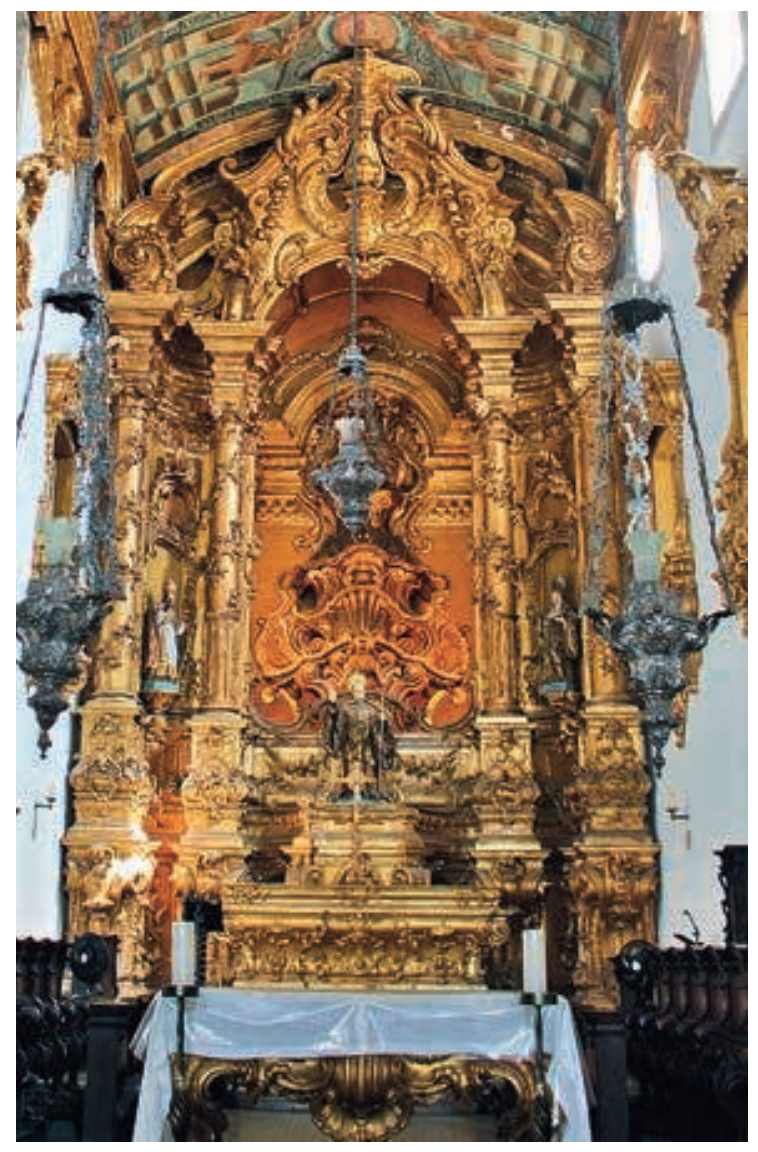

appartenant à une culture vers une autre culture. Or sommes-nous bien, au XVIII ${ }^{\mathrm{e}}$ siècle, en présence de deux cultures différenciées des deux côtés de l'Atlantique ? Et quelle notion de culture ces objets nous forcent-ils à considérer ? Je présenterai ensuite les connaissances que les historiens de l'art ont accumulées sur ces deux retables et les analyses qu'ils en ont proposées. Je me demanderai enfin s'il y a bien eu « transfert " et si l'histoire de l'art est capable de répondre à la question de savoir si ces objets ont apporté quelque chose de leur éventuelle culture d'origine qui puisse avoir été à la source de quoi que ce soit de culturellement important dans l'éventuelle culture d'accueil.

\section{Un transfert de quelle culture vers quelle culture ?}

L'histoire même de la prise de conscience ou de l'invention d'une identité culturelle propre a longtemps été hésitante au Portugal comme au Brésil, et le rôle joué par les arts plastiques dans ces affaires a souvent été mineur ${ }^{11}$. Du côté portugais, les histoires nationales de l'art continuent d'hésiter entre histoires de l'art au Portugal et histoires de l'art portugais, et la tentation a existé de considérer que l'art savant 


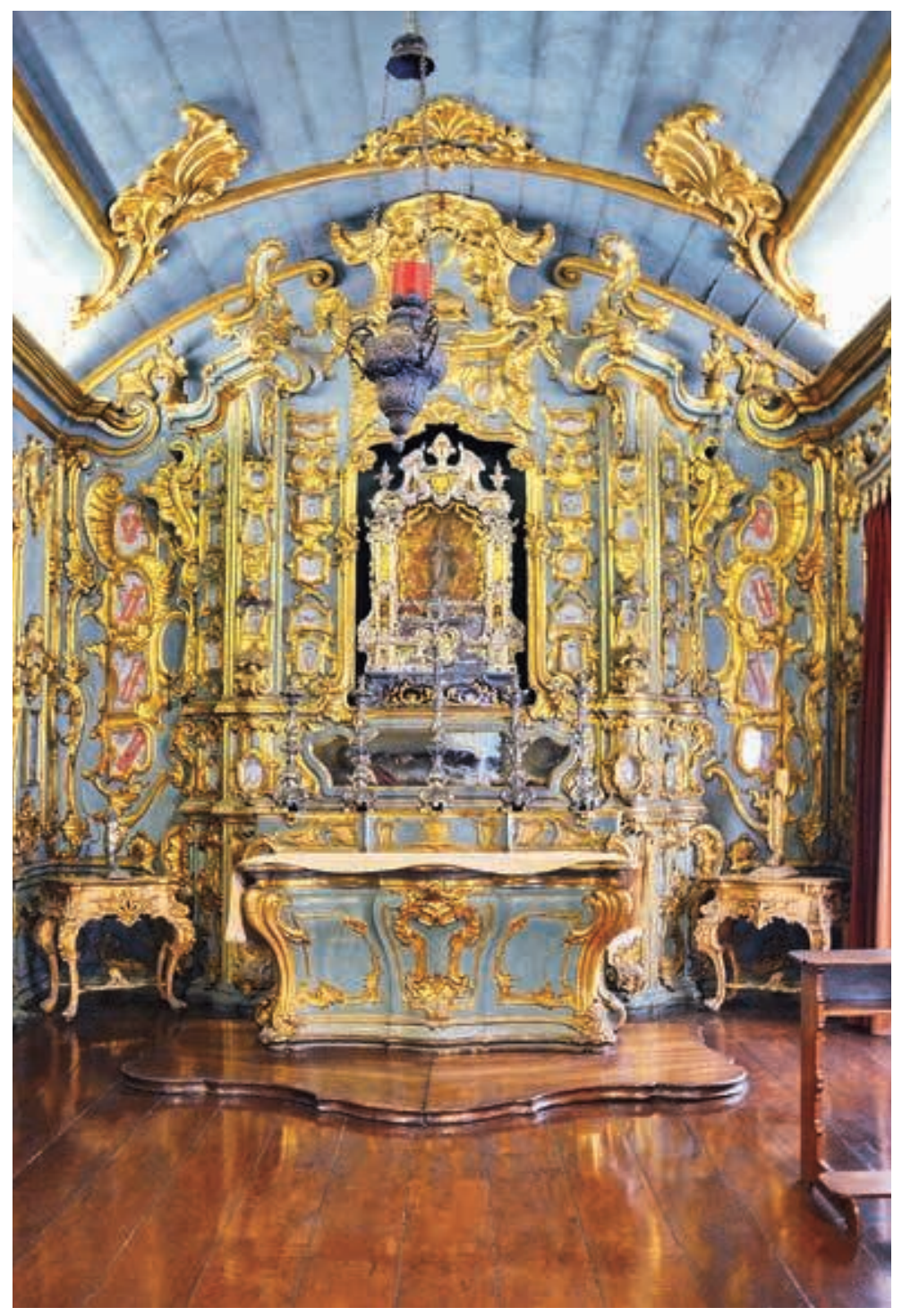

avait été essentiellement d'inspiration étrangère et que seul l'art populaire pouvait représenter l'art authentiquement portugais ${ }^{12}$. Du côté brésilien, un tenace sentiment 2. Retable de la chapelle des reliques de l'église du monastère bénédictin de Rio de Janeiro, vers 1760-1769. d'infériorité a longtemps prédominé et ce n'est que dans les années 1930 que Gilberto Freyre a su retourner les stigmates du préjugé contre le métissage qui caractérisait une grande partie de la population du pays pour en faire une valeur positive d'identification $^{13}$, dont l'incarnation artistique idéale pouvait être la figure d'António Francisco Lisboa (1738-1814), dit «O Aleijadinho ", né d'un père portugais et d'une esclave noire $\mathrm{d}^{\text {'origine africaine }}{ }^{14}$.

Mais ces recherches d'identification nationale ne sont que des vues a posteriori et la question qui me semble la plus pertinente à poser au regard de la problématique d'un éventuel transfert culturel est la suivante : la culture du Brésil colonial est-elle réellement autre par rapport à la culture du Portugal continental ? Gauvin Alexander Bailey le rappelle : 
Une part significative de l'élite militaire, économique et ecclésiastique du Portugal soit venait du Brésil soit y avait séjourné longuement [...] et la croissance rapide de la population du Brésil tout comme le rôle crucial que le pays jouait dans le bien-être économique et géopolitique du Portugal poussaient l'intellectuel portugais dom Luis da Cunha (1662-1749) à recommander dès 1738 que la cour s'installe à Rio de Janeiro ${ }^{15}$.

Et à la question de savoir si la culture brésilienne et la culture portugaise sont différentes dans le domaine des retables, qui est celui qui nous intéresse ici, Francisco Lameira répond très clairement dans sa récente synthèse consacrée aux retables du monde portugais : le seul centre artistique véritable serait Lisbonne et ce serait de la capitale portugaise que se propageraient les modèles vers les autres régions ${ }^{16}$. Il enfonce même le clou, un peu plus loin dans son texte : à l'exception des territoires asiatiques, les quelques spécificités régionales qui se vérifient un peu partout ne seraient que ponctuelles et restreintes à certains ateliers, les divers degrés d'assimilation des normes venues de Lisbonne suffisant à expliquer les autres différences constatées ${ }^{17}$. Il me semble cependant que les retables datant de la seconde moitié du XVIII ${ }^{\text {e }}$ siècle dans le Minho contredisent quelque peu cette affirmation car l'adoption de l'ornement " rococo " y a été plus radicale que n'importe où ailleurs au Portugal, mais il est vrai que cette spécificité peut paraître d'une nature plus générale que celles envisagées par Lameira. Celui-ci distingue d'ailleurs deux grands centres dans la métropole, celui de l'Entre Douro e Minho (Porto et Braga) et celui de l'Estrémadure (Lisbonne), tandis qu'il ne trouve au Brésil que des centres de moyenne dimension, dont ceux de Rio de Janeiro et de la région du Pernambouc (Olinda et Recife), qui nous intéressent particulièrement ici ${ }^{18}$. Peut-être faut-il dès lors y regarder de plus près pour essayer de distinguer les éventuelles cultures en jeux, cultures qu'on nous dit ne pas pouvoir différencier clairement.

\section{Le retable principal de l'église bénédictine $d^{\prime}$ Olinda}

La critique est loin d'avoir négligé le retable d'Olinda puisqu'il figure dans tous les principaux ouvrages qui intègrent l'art de la région du Pernambouc au XVIII ${ }^{e}$ siècle et qu'il a même connu le singulier destin d'être exposé dans le hall du Solomon R. Guggenheim Museum à New York, entre octobre 2001 et mai 2002 pendant l'exposition « Brazil: Body and Soul ${ }^{19}$ "! Mais, au-delà de la reconnaissance de sa qualité et de son importance historique, il a été, à ma connaissance, assez peu analysé. Assez tôt relié stylistiquement au retable principal de l'église bénédictine de Tibães (1756-1761 ; fig. 3), notamment par Martin Sória et Germain Bazin, il a plus précisément été " associé " par Robert C. Smith à l'art de frère José Vilaça (1731-1809) 20. Myriam Andrade Ribeiro de Oliveira, si elle rappelle les relations évidentes avec le retable principal de Tibães, estime, dans la suite de Bazin, que la décoration des fûts et des bases des colonnes elles-mêmes appartient « au répertoire de la taille de la région ${ }^{21}$ ". De même, dans leur ouvrage sur les retables du Brésil colonial, Francisco Lameira, Mozart Bonazzi da Costa et Martina del Rio João, affirment que le dessin de frère José Vilaça est " réinterprété localement par le maître responsable de sa réalisation sculpturale ${ }^{22} »$. Le retable est en effet réalisé en bois de cèdre ${ }^{23}$, essence d'utilisation beaucoup plus courante au Brésil qu'au Portugal, où on lui préfère le bois de châtaignier ${ }^{24}$. La précision n'est pas sans intérêt puisque l'on sait que quelques retables ont été fabriqués au Portugal pour être envoyés ensuite au Brésil, et même au moins l'un d'entre eux devait être exécuté dans la métropole d'après un dessin envoyé de Rio de Janeiro ${ }^{25}$ ! Sans que jamais l'expression ne soit utilisée, il me semble donc clair que, pour la critique, nous sommes en présence d'un transfert culturel puisque, d'une part, 
la conception de l'ouvrage serait le produit d'une culture visuelle d'inspiration « rococo » qui apparaît dans le Nord-Ouest portugais, autour de la ville de Braga, à partir des années 1750 et qui s'exprime notamment dans les décorations d'églises, et puisque, d'autre part, son exécution le distingue suffisamment des exemples portugais, ne serait-ce que par le bois utilisé, pour porter à croire en l'interprétation locale d'un entailleur du Pernambouc, éventuellement encore marqué par les exemples de la génération antérieure.

Il serait même possible d'affiner cette analyse du point de vue de la " culture de départ ». Si le retable d'Olinda présente d'évidentes affinités avec les retables dorés d'inspiration " rococo " imaginés par frère José Vilaça et déclinant le modèle de Tibães, on peut aussi le rapprocher des ouvrages tardifs de l'artiste, appartenant à ce que Smith appelait son " troisième style ", et qu'il considérait comme un compromis raté avec un retour à des normes classiques. On pense notamment au retable principal de Pendorada (1780-1786), exécuté en même temps que celui d'Olinda mais avec une polychromie nouvelle qui ne facilite pas la comparaison. L'affirmation de Bazin, antérieure aux travaux de Smith, selon laquelle « le style [du retable d'Olinda] est certainement plus évolué [que celui du retable de Tibães], car il est déjà touché de quelques prodromes du néo-classicisme ${ }^{26}$ ", n'est donc pas un argument pour distinguer le retable d'Olinda de l'œuvre du moine artiste, comme le pensait son auteur, mais permet au contraire de l'en rapprocher. Le retable d'Olinda reflète donc les transformations de l'art de frère José Vilaça d'une manière plus fidèle que ne l'a perçu la critique jusqu'à présent, et les écarts d'exécution en apparaissent d'autant plus mineurs.

On pourrait dès lors croire que les historiens ont eu l'intuition d'une culture de départ et d'une culture d'arrivée, et ajouter que Smith a proposé d'identifier le "passeur " de ce " transfert " avec l'abbé frère Miguel Arcanjo da Anunciação qui avait lancé la reconstruction du chœur de l'église en 1778 et devait avoir vu le retable de Tibães lors des réunions triennales de la congrégation bénédictine ${ }^{27}$ et sans doute rencontré aussi directement le frère José Vilaça. Il semblerait donc que tous les éléments nécessaires à la reconnaissance d'un « transfert culturel " aient été identifiés sans que son analyse n'ait jamais été explicitée. Mais en constatant que ce " transfert culturel » est en réalité le transfert partiel d'une culture visuelle ne s'approche-t-on pas d'une analyse qui rend aux vieilles catégories stylistico-formelles un rôle prépondérant? Et si, comme l'écrit Michel Espagne, " c'est moins la circulation des biens culturels que leur réinterprétation qui est en $\mathrm{jeu}^{28}$ ", nous nous trouvons plutôt démunis pour saisir cette réinterprétation face au peu d'ouvrages qui montrent un écho du retable d'Olinda et qui semblent se résumer à l'œuvre de José Gomes de Figueiredo, à qui Smith attribue

3. André Soares, José Á Ivares de Araújo et José Ferreira Vilaça, João Gonçalves Ribas, retable principal, église du monastère São Martinho, Tibães, 1756-1761.

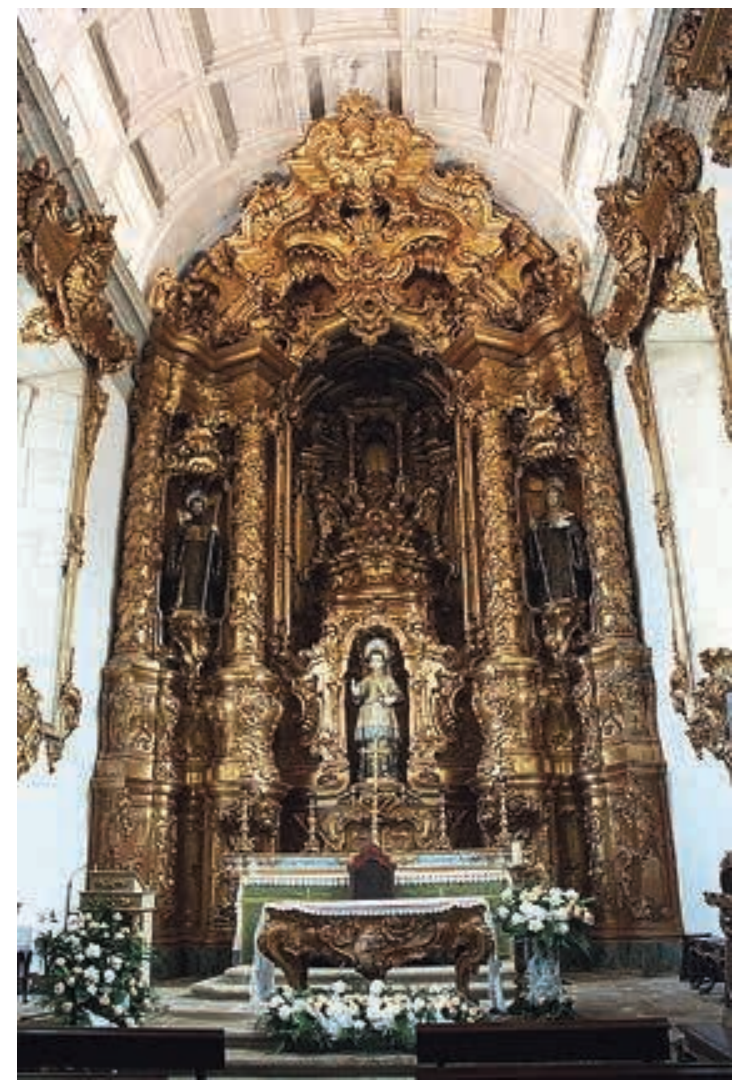


la réalisation du retable d'Olinda et de la talha de son chœur, en la rapprochant de ses ouvrages documentés (de 1787) ou de ceux qui lui sont attribués dans l'église São Pedro dos Clérigos, à Recife ${ }^{29}$. Il semble que, comme le pressentait Joyeux-Prunel, ici le transfert n'était pas « tant un transfert entre ensembles culturels, qu'une dynamique entre groupes sociaux, économiques, politiques ; [...] où les jeux des individus ont une importance essentielle ${ }^{30} »$. La notion de transfert culturel ne redonnerait-elle pas, en fin de compte, de l'importance aux artistes en tant qu'individus ?

\section{Le retable de la chapelle des reliques de l'église du monastère bénédictin de Rio de Janeiro}

Dans son important ouvrage de synthèse sur le " rococo " religieux au Brésil et ses antécédents européens, Myriam Andrade Ribeiro de Oliveira date la décoration de la chapelle des reliques de 1760-1769 et estime qu'il s'agit de la plus ancienne des décorations de ce genre existant encore à Rio de Janeiro, bien qu'elle date de 1753 les premières manifestations du " rococo " dans la ville, pionnière en la matière au Brésil ${ }^{31}$. Sans attribution certaine, le décor de la chapelle pourrait avoir inauguré la pratique du revêtement intégral par des lambris de bois incluant de fins cadres dorés qui délimitent les emplacements réservés à la peinture et aux reliefs ornementaux. L'historienne pense que ce parti, caractéristique des ambiances les plus luxueuses du " rococo » de Rio, renvoie aux décorations du " rococo " civil français, diffusés par la gravure, et estime également que le retable s'inspire du " rococo " germanique, via les gravures d'Augsbourg. Elle souligne enfin que sa typologie n'a pas connu de postérité à Rio de Janeiro, " peut-être à cause de sa complexité ornementale, hors des canons de la tradition luso-brésilienne ${ }^{32}$ ".

Il est très caractéristique que Ribeiro de Oliveira situe l'ouvrage à la fois à l'origine d'une pratique propre à Rio de Janeiro et hors de celle-ci, sans proposer l'éventualité d'une paternité portugaise, alors même qu'elle se montre très attentive aux antécédents portugais et notamment minhotes du " rococo " brésilien. Il est vrai que lors de la parution de son ouvrage, en 2003, ni Eduardo Pires de Oliveira ni moi-même n'avions encore présenté les résultats de nos recherches sur André Soares et sur le " rococo minhote ", qui ne seront rendues publiques qu'en 2011 et 2014 respectivement ${ }^{33}$. Et ce n'est qu'en 2016 qu'une possible attribution à André Soares est prudemment envisagée, fondée sur les liens du commanditaire, l'abbé bénédictin et évêque de Rio de Janeiro dom António Malheiro Reimão (1694-1773), avec la ville minhote de Viana do Castelo où sa famille possédait une magnifique maison dont il finança la construction de la chapelle, à partir de 1758, et notamment la réalisation de son retable, en 1763, conçu par André Soares selon Pires de Oliveira ${ }^{34}$.

Les ouvrages stylistiquement les plus proches de la chapelle des reliques de Rio de Janeiro se trouvent en effet dans le Minho. Ils sont généralement peu connus, d'un accès parfois difficile, et ont été fort peu étudiés : l'armoire-reliquaire de la sacristie de l'ancienne église bénédictine d'Arcos de Valdevez; le retable de la chapelle Nossa Senhora da Lapa de Fão (Esposende), datant peut-être de 1760, et le retable de la chapelle Sainte-Rita de la Casa Barbosa, à Arcozelo (fig. 4), peut-être de 1768, étudiés par Pires de Oliveira (et attribués à André Soares ${ }^{35}$ ) ; le retable de la chapelle de la sainte parenté de l'église de Real (Braga) ; le retable de l'église d'Outeiro (Cabeceiras de Basto) peutêtre des années 1760. Tous ces ouvrages préfèrent les pilastres aux colonnes et, surtout, présentent, comme à Rio, un dynamisme des lignes un peu désordonné et des rocailles qui semblent plaquées sur des surfaces parfois ondulantes. Bien qu'un certain air de famille 


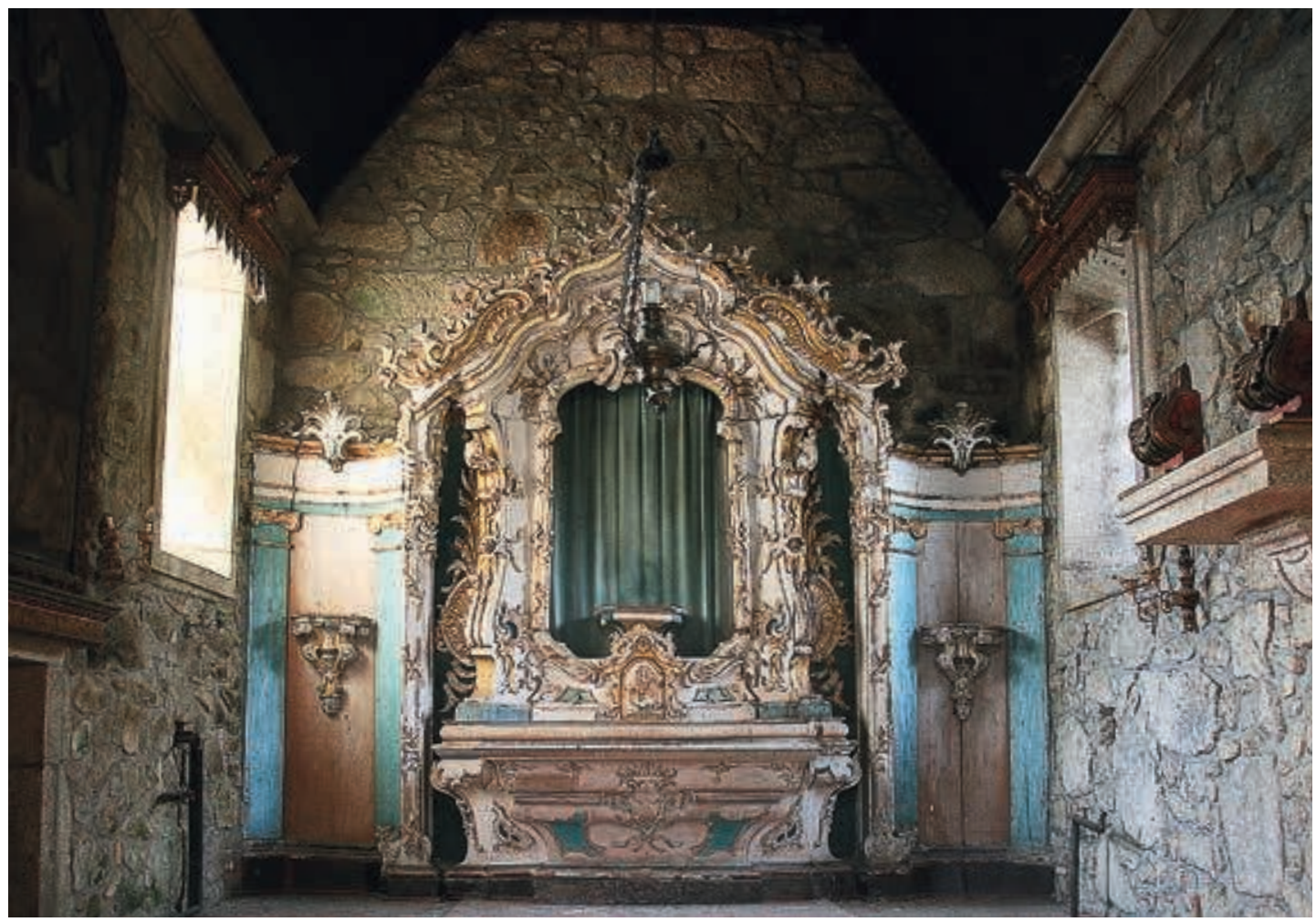

permette de les situer en effet dans l'entourage d'André Soares, ces caractéristiques plus particulières sont 4. Retable de la chapelle Sainte-Rita de la Casa Barbosa, Arcozelo (Vila Verde), 1768 (?). assez éloignées de l'ornementation presque organique qu'il utilise et ne reflètent pas sa capacité à projeter dans l'espace. C'est pourquoi j'ai hypothétiquement associé ces ouvrages au retable principal de l'église de Caldelas, aux caractéristiques plus proches, le seul retable dont on soit sûr qu'il a été dessiné, en 1760, par son frère, le père António Soares da Silva (1716-1770) ${ }^{36}$.

L'extension latérale du retable de la chapelle Sainte-Rita de la Casa Barbosa le rapproche beaucoup de ce qui se passe à Rio. Cependant, on peut constater qu'aucun des ouvrages mentionnés dans le Minho ne s'étend à l'ensemble de la pièce où il se trouve. Or l'une des caractéristiques principales, et celle qui a fait fortune ensuite à Rio, selon Ribeiro de Oliveira, c'est justement l'occupation totale de l'espace de la chapelle par des lambris. Le Minho possède lui aussi des chapelles entièrement décorées de lambris mais elles sont postérieures à celle de Rio, comme le chœur de Pombeiro de 1773-1776, entièrement conçu par frère José Vilaça, le chœur de l'église de pèlerinage Nossa Senhora da Agonia de Viana do Castelo, datant sans doute de 1780-1781 ou la chapelle du Saint-Sacrement du couvent bénédictin São Miguel de Refójos, à Cabeceiras de Basto, réalisée en 1780-178937. Les chapelles ornées de lambris ne sont donc pas étrangères à la culture décorative minhote et il n'est pas impossible que les plans de celle de Rio ait été connus dans le Minho, et en particulier à Viana do Castelo.

Par ailleurs, le commanditaire déjà évoqué de la chapelle de Rio, dom António do Desterro (1694-1773), prolonge une relation déjà ancienne de la famille avec le Brésil $^{38}$. Son oncle Balthazar Malheiro da Neiva († 1736) avait en effet hérité d'un oncle 
de son épouse, établi dans la ville brésilienne de Salvador da Bahía, et avait légué cet héritage dès 1716 au père de dom António. L'aîné de dom António, Gaspar Malheiro Reimão, hérite de son père et de son oncle, mais aussi des rentes brésiliennes de deux de leurs frères, ce qui lui permet d'élargir leur propriété dans la région de Ponte de Lima et de construire la Casa da Praça à Viana do Castelo dont la chapelle, dédiée à saint François de Paul, déjà évoquée, est élevée aux frais de dom António à partir de 1758, et consacrée en 1766. Les relations de cette famille avec le Brésil étaient donc relativement anciennes et on peut imaginer que ses rapports au monde de l'art minhote incluaient les meilleurs parmi ses concepteurs et exécutants. Il semble donc tout à fait plausible de penser que le retable de Rio de Janeiro ait pu être conçu par l'un de ces créateurs, qu'il s'agisse d'André Soares, de son frère António, ou de quelqu'un de leur entourage, d'autant plus que le retable de Rio possède une sorte de postérité à Viana même.

Voilà ce qu'il est possible de dire à propos de l'identification de la culture de départ - celle des « curieux » de Braga, ces concepteurs qui ne sont pas de véritables professionnels mais jouissent de suffisamment de temps et de moyens pour pouvoir se consacrer à un art qu'ils conçoivent comme libéral, et qui puisent dans les gravures parisiennes et augsbourgeoises leur inspiration - et de celle du passeur, un religieux d'origine aristocratique intégré à la fois au réseau bénédictin et à celui de sa famille au Brésil. Plus assurément que dans le cas d'Olinda, il est possible aussi de dire quelque chose sur la culture d'arrivée, celle des entailleurs de Rio de Janeiro. Nancy Rabelo explique ainsi l'absence de répercussion du modèle de la chapelle des reliques (plus relative qu'elle ne l'affirme à vrai dire si l'on en croit Ribeiro de Oliveira ${ }^{39}$ ) par la prépondérance du modèle du " rococo » de Porto, qui se distingue en particulier par l'usage de colonnes torses, abandonnées dans le Minho ${ }^{40}$ : Rio pourrait ainsi être l'un de ces " portails sur la globalité " qu'évoquait Michel Espagne ${ }^{41}$, où la connaissance d'autres sources (non seulement les gravures augsbourgeoises mais aussi le " rococo " de Porto, notamment) rend possible une métamorphose du modèle hors de toute relation hiérarchique de centre à périphérie.

L'analyse de ces deux études de cas en tant que « transferts culturels " montre la nécessité d'une connaissance très fine de tout ce qui entoure les objets pour être menée à bien. À ce jour, les savoirs concernant le Minho, Olinda et Rio de Janeiro au XVIII ${ }^{\mathrm{e}}$ siècle restent très parcellaires, et ont été construits en grande partie sans que les enquêteurs aient eu à l'esprit l'idée d'appliquer un tel modèle. Si la notion de transfert culturel, lorsque son application est possible, peut apporter un point de vue plus juste et donc produire une image plus favorable de cultures qui sont négligées ou méprisées de par leur statut supposément périphérique, elle ne peut faire l'économie de recherches plus traditionnelles, autour de questions formelles ou de paternité notamment. Mais n'est-ce pas là une chance de revitaliser ces questions qu'une partie de la recherche académique semble avoir abandonnées et de focaliser à nouveau notre attention sur les ouvres elles-mêmes ? 


\section{Raúl C. Sampaio Lopes}

Actuellement maître de conférences en histoire de l'art au département de culture visuelle de la Korea University (Séoul), Raúl C. Sampaio Lopes est docteur en histoire de l'art moderne. Il a soutenu sa thèse, intitulée « Le Rococo minhote : I'art dans la province de Braga dans la seconde moitié du XVIII ${ }^{\mathrm{e}}$ siècle", sous la direction de Daniel Rabreau, à I'université Paris 1 - Panthéon-Sorbonne en 2014. En collaboration avec Francisco Lameira et José João Loureiro, il a écrit l'ouvrage Retábulos na Arquidiocese de Braga (Faro, Universidade do Algarve, 2020).

\section{NOTES}

1. Dans cet article, je me base sur la notion de transfert culturel telle qu'elle est présentée par Michel Espagne, dans "La notion de transfert culturel ", Revue Sciences/ Lettres, no 1, 2013 [DOI : 10.4000/rsl.219]. Pour une discussion critique de cette notion, voir Béatrice JoyeuxPrunel, "Les transferts culturels, un discours de la méthode ", Hypothèses, vol. 6, n 1, 2003, p. 149-162 [DOI : 10.3917/hyp.021.0149].

2. Voir Marie-Thérèse Mandroux-França, «Information artistique et "mass media" au XVIII e siècle : la diffusion de l'ornement gravé rococo au Portugal ", Bracara Augusta, vol. 17, no 64 (76), 1973, p. 412-445, et eadem, "L'image ornementale et la littérature artistique importées du XVI ${ }^{\mathrm{e}}$ au XVIII ${ }^{\mathrm{e}}$ siècle : un patrimoine méconnu des bibliothèques et musées portugais ", Boletim cultural. Câmara municipal do Porto, $2^{\mathrm{e}}$ série, vol. 1, 1983, p. 143-205.

3. Les classifications stylistiques décrivent mal la dynamique, l'hybridité et la fluidité de l'évolution artistique. Dans cet article, j'utilise donc le terme « rococo » par commodité taxonomique mais le place entre guillemets pour souligner son usage très approximatif. Pour une explicitation des catégories stylistiques adaptées à la réalité portugaise, voir par exemple Francisco Lameira, Retábulos no mundo português, Faro, Universidade do Algarve, 2020, p. 146-178.

4. Voir Raúl C. Sampaio Lopes, "Quand domine un art mineur : des difficultés soulevées par l'étude de la réception de la rocaille dans la province de Braga ", Nouvelle Revue d'esthétique, vol. 16, nº 2, 2015, p. 24 [DOI : 10.3917/nre.016.0011]. L'image était déjà proposée dans Raúl Cristóvão Sampaio Lopes, "Le Rococo minhote, l'art dans la province de Braga dans la seconde moitié du XVIII" siècle ", thèse de doctorat en histoire de l'art, Daniel Rabreau (dir.), université Paris 1 - PanthéonSorbonne, 2014, vol. 1, p. 290 et p. 349.

5. Je voudrais ressusciter ici ce vieux mot français pour traduire le portugais entalhador, qui désigne l'artiste de la talha, car il permet de souligner la différence du monde artistique portugais, colonies comprises, tout en évitant le recours à un mot étranger. II est significatif, du point de vue de la valeur culturelle donnée à cet art au Portugal, que le mot ait survécu en portugais alors qu'il a disparu en français. Dans les textes anciens, le terme escultor (" sculpteur ») est plus souvent synonyme $d^{\prime}$ « imagier » mais il arrive que l'entailleur sculpte aussi des statues, les limites déterminées par certains textes régulateurs résistant mal aux nécessités pratiques.

6. Voir en particulier Robert C. Smith, Frei José de Santo António Ferreira Vilaça, escultor beneditino do século XVIII, Lisbonne, fondation Calouste Gulbenkian, 1972, et idem, André Soares, arquitecto do Minho, Lisbonne, Horizonte, 1973.

7. Eduardo Alberto Pires de Oliveira, «André Soares e o rococó do Minho ", thèse de doctorat, Manuel Joaquim Moreira da Rocha (dir.), Porto, Universidade do Porto, 2011 [URL : repositorioaberto.up.pt/handle /10216/62456].

8. Voir Jens Baumgarten et André Tavares, «Le baroque colonisateur : principales orientations théoriques dans la production historiographique ", Perspective : actualité en histoire de l'art, no 2, 2013 [DOI : 10.4000/perspective. 3888].

9. Voir Espagne, 2013, cité n. 1.

10. Voir Joyeux-Prunel, 2003, cité n. 1.

11. Ronald $\mathrm{H}$. Chilcote peut ainsi écrire un livre de 235 pages sur la recherche d'une identité nationale par les intellectuels brésiliens sans mentionner les arts plastiques : voir Ronald H. Chilcote, Intellectuals and the Search for National Identity in Twentieth-Century Brazil, New York, Cambridge University Press, 2014.

12. Pour une histoire de l'histoire de l'art au Portugal, voir Paulo Pereira, "História da história da arte portuguesa », dans Fernando Guimarães, Paulo Pereira et al., Em torno da história da arte, Vila Nova de Gaia, Fubu Editores, 2009, p. 31-87. Pour l'alternance entre la recherche d'une essence portugaise dans l'art savant et dans l'art populaire, voir, dans le même ouvrage, la contribution de José Alberto Seabra Carvalho et Marta Barreira Carvalho, «Museus e exposições: ideias, formas e discursos de representação e celebração da arte portuguesa (do Liberalismo ao Estado Novo) », p. 89-142, constitué de deux parties, la première consacrée à l'« école portugaise » comme représentation de l'essence de la personnalité artistique d'un pays et la seconde à l'archéologie et à la culture populaire comme modes alternatifs du discours nationaliste.

13. Pour une présentation du contexte d'élaboration des idées de Gilberto Freyre et sa critique actuelle, voir Maria Lúcia G. Pallares-Burke, "Gilberto Freyre and Brazilian Self-Perception », dans Francisco Bethencourt et Adrian Pearce (dir.), Racism and Ethnic Relations in the Portuguese-Speaking World, Oxford / New York, Oxford University Press, 2012, p. 112-132.

14. Voir Baumgarten et Tavares, 2013, cité n. 8.

15. «A significant proportion of Portugal's military, mercantile, and ecclesiastical elite either came from Brazil or spent a long time there [...] and Brazil's rapidly growing population and critical role in Portugal's economic and geopolitical well-being meant that as early as 1738 the Portuguese intellectual Dom Luis da Cunha (1662-1749) was recommending that the court move to Rio de Janeiro. » Gauvin Alexander Bailey, The Spiritual Rococo: Decor and Divinity from the 
Salons of Paris to the Missions of Patagonia, Burlington, Ashgate, 2014, p. 197.

16. Lameira, 2020, cité n. 3, p. 93.

17. Ibidem, p. 98-99.

18. Ibidem, p. 141-143.

19. Organisée peu après les commémorations du cinquième centenaire de la « découverte » du Brésil, l'exposition « Brazil: Body and Soul » avait pour but explicite de donner à un public international une image riche et diversifiée du pays à travers ses multiples expressions artistiques (voir la préface d'Edemar Cid Ferreira, directeur de l'association à but non lucratif BrasilConnects, co-responsable de l'organisation de l'exposition avec le musée américain, dans Edward J. Sullivan (dir.), Brazil: Body and Soul, cat. exp. (New York, Solomon R. Guggenheim Museum, 2001-2002 ; Bilbao, musée Guggenheim, 2002), New York, Guggenheim Museum, 2001, p. vii). Le catalogue propose une contextualisation du retable (Augusto C. da Silva Telles, "The Main Altar of São Bento de Olinda ", dans ibidem, p. 150-154), une notice propre (Edward J. Sullivan, " Main Altar, São Bento de Olinda ", dans ibidem, p. 156) et des photographies d'ensemble et de détails (ibidem, p. 158-163).

20. Smith, 1972, cité n. 6, vol. 2, p. 406-416.

21. "Pertencem ao reportório da talha da própria região. ", Myriam Andrade Ribeiro de Oliveira, $O$ Rococó religioso no Brasil e seus antecedentes europeus, São Paulo, Cosac \& Naify, 2003, p. 208.

22. «É reinterpretado localmente pelo mestre responsável pelo seu entalhe ", Francisco Lameira, Mozart Bonazzi da Costa et Martina del Rio João, Retábulos no Brasil colonial, Faro, Universidade do Algarve, 2020, p. 117. Le retable est reproduit en pleine page dans ce même ouvrage, p. 181.

23. Voir Sullivan, 2001, cité n. 19, p. 156.

24. Voir Lameira, 2020, cité n. 3, p. 104 et Lameira, Bonazzi da Costa et del Rio João, 2020, cité n. 22, p. 47.

25. Ibidem, p. 85-86.

26. Citation tirée de Smith, 1972, cité n. 6, vol. 2, p. 416, note 1. La remarque est reprise sans indication de source dans Sullivan, 2001, cité n. 19, p. 156.

27. Smith, 1972, cité n. 6, vol. 2, p. 406.

28. Espagne, 2013, cité n. 1, paragraphe 1.

29. Sur cet artiste, voir les brèves remarques et références données dans Smith, 1972, cité n. 6, vol. 2, p. 416, note 1. Il faut noter que le retable principal de l'église du couvent Santa Teresa d'Olinda, qu'on a cru pouvoir inclure dans la descendance de celui de São Bento, est considéré comme antérieur, des années 1770, dans Lameira, Bonazzi da Costa et del Rio João, 2020, cité n. 22, p. 173.

30. Joyeux-Prunel, 2003, cité n. 1.

31. Ribeiro de Oliveira, 2003, cité n. 21, p. 183-184.

32. "Essa tipologia de retábulo não teve posteridade na talha do Rio de Janeiro, talvez em função de sua complexidade ornamental, fora dos padrões da tradição luso-brasileira. » Ibidem, p. 185.

33. Voir Pires de Oliveira, 2011, cité n. 7, et Sampaio Lopes, 2014, cité n. 4.
34. Francisco Lameira, Carlos Evaristo et José João Loureiro, Retábulos relicários, Faro, Universidade do Algarve, 2016, p. 227.

35. Outre sa thèse et en ce qui concerne le second de ces retables, voir Eduardo Pires de Oliveira, André Soares em Vila Verde, Vila Verde, Município de Vila Verde, 2016. Les belles photographies de Luís Leite permettent d'étudier l'ouvrage en détail.

36. Voir Sampaio Lopes, 2014, cité n. 4, vol. 1, p. 371 383 et Raúl C. Sampaio Lopes, « Achegas para a actividade artística do Padre António Soares da Silva (1716-1770) no âmbito do rococó minhoto ", article à paraître dans Promontoria, revista do departamento de história, arquelogia e património da universidade do Algarve. Dans ce dernier article, j'attribue désormais la conception des retables de Fão, de Pico de Regalados, de la Casa Barbosa à Arcozelo (Vila Verde) et de la sacristie de l'église Pópulo au père António Soares da Silva et non plus à André Soares.

37. Les documents sur l'église de Viana do Castelo ont été regroupés dans Pires de Oliveira, 2011, cité n. 7, vol. 2, p. 334-348. Sur les ouvrages de Pombeiro et Refójos de Basto, la référence reste Smith, 1972, cité n. 6, qui les évoque à de multiples reprises de manière dispersée.

38. Voir Anne de Stoop, Arquitectura senhorial do Minho, Porto, Caminhos Romanos, 2015, p. 373-377.

39. Ribeiro de Oliveira, 2003, cité n. 21, p. 184-185.

40. Nancy Regina Mathias Rabelo, "A originalidade da Obra de Ignácio Ferreira Pinto no contexto da talha carioca na segunda metade do século XVIII ", mémoire de maîtrise en histoire et théorie de l'art, Rio de Janeiro, Universidade Federal do Rio de Janeiro, 2001, p. 93-94.

41. Espagne, 2013, cité n. 1, paragraphe 19. 